\title{
Acute Mitral Valve Injury Following Percutaneous Left Atrial Appendage Occlusion: A Case Report and Literature Review
}

\author{
Xuejun Sun, MD,${ }^{1}$ Dandan Hong, MD,${ }^{2}$ Haibo Liu, MD, ${ }^{1}$ Hongmu Li, MD ${ }^{1}$ \\ ${ }^{1}$ Department of Cardiovascular Surgery, Fujian Medical University Affiliated First Quanzhou Hospital, Quanzhou, China; ${ }^{2}$ Department \\ of Echocardiography, Fujian Medical University Affiliated First Quanzhou Hospital, Quanzhou, China
}

\section{ABSTRACT}

Acute mitral valve injury following percutaneous left atrial appendage (LAA) occlusion is a rare, but potentially life-threatening complication. This report presents a case of severe mitral valve injury following left atrial appendage occlusion (LAAO) that required mitral valve replacement. The LAAO device successfully was removed, and the LAA was closed with a double-running polypropylene suture. In addition, the mitral valve was replaced with an artificial valve. The patient had an uneventful clinical evolution and was discharged 10 days after emergency surgery.

\section{INTRODUCTION}

Atrial fibrillation is one of the most common clinical arrhythmias that occurs in thromboembolism and is the main cause of death or disability in patients [January 2019; Gutierrez 2016]. In patients with non-valvular atrial fibrillation, up to $90 \%$ of thrombi come from the left atrial appendage (LAA) [Loupis 2014]. The efficacy of oral anticoagulation (OAC) for stroke prevention in patients with non rheumatic atrial fibrillation (AF) clearly has been established but has had many drawbacks. Percutaneous left atrial appendage occlusion (LAAO) can be used as an alternative for patients who cannot use oral anticoagulants due to recent or previous bleeding, pregnancy, and so on [Jazayeri 2017]. WATCHMAN (Boston Scientific, USA) is the most widely used LAAO device with the most evidence and longest follow-up time [Windecker 2014]. This report presents a case of acute mitral valve injury following LAAO that requires mitral valve replacement.

\section{CASE REPORT}

A 67-year-old man presented with permanent $\mathrm{AF}$, and anticoagulation therapy was established. The patient suffered from a small cerebral infarction three months prior.

Received fune 21, 2020; accepted August 11, 2020.

Correspondence: Hongmu Li, MD, Department of Cardiovascular Surgery, Fujian Medical University Affiliated First Quanzhou Hospital, 362000 Quanzhou,China (e-mail: libm25@mail3.sysu.edu.cn).
Due to poor compliance, percutaneous LAAO was proposed. The patient's CHADS2 and HAS-BLEDS score was 3. Percutaneous LAAO was performed on May 15, 2020. Transesophageal echocardiography (TEE) and angiography were used to measure the inner diameter of the LAA, and a 32-mm WATCHMAN device was implanted (Figure A and B). The intraoperative test revealed that the device works well. (Figure C and D). However, the postoperative TEE and angiography revealed the migration and entrapment of the LAAO device in the mitral valve (Figure $\mathrm{E}$ and $\mathrm{F}$ ), which resulted in massive mitral regurgitation and hemodynamic instability, forcing emergency cardiac surgery (Figure G). During the open surgical procedure, the LAAO device was found to be hooked to the mitral valve tendon, causing severe damage to the leaflets (Figure H). The device was successfully removed, and the LAA was closed with a double-running polypropylene suture during the open surgery. In addition, the mitral valve was replaced with an artificial valve. TEE revealed the artificial valve works well after surgery (Figure I). The patient had an uneventful clinical evolution and was discharged 10 days after the surgery.

\section{DISCUSSION}

Atrial fibrillation always produces a blood clot and may cause emboli, which in turn can cause ischemic damage to the brain, kidney, or other organs supplied by the systemic circulation. Oral anticoagulants, such as warfarin, can effectively prevent atrial fibrillation embolism, but require lifelong medication, and the treatment window is narrow. Furthermore, there is a risk of bleeding, and long-term compliance is poor. The efficacy and safety of LAAO in preventing AF embolism has been continuously improved, and this has been included into the European Heart Association (ESC) atrial fibrillation treatment guidelines [Camm 2012].

It is very rare for the LAAO device to detach and damage the mitral valve [Yilmaz 2019]. The abnormal shape of the LAA, inappropriate size of the LAAO device, and sudden turning of the $\mathrm{AF}$ into a sinus rhythm are the common causes of shedding [Jazayeri 2017; Gonzalez-Santos 2013]. There are no reports on percutaneous retrieval, which often requires surgery, especially when the device becomes stuck in the mitral valve chordae [Yilmaz 2019; El-Gabry 2018; Gupta 2013]. The surgical removal of the LAAO device also 

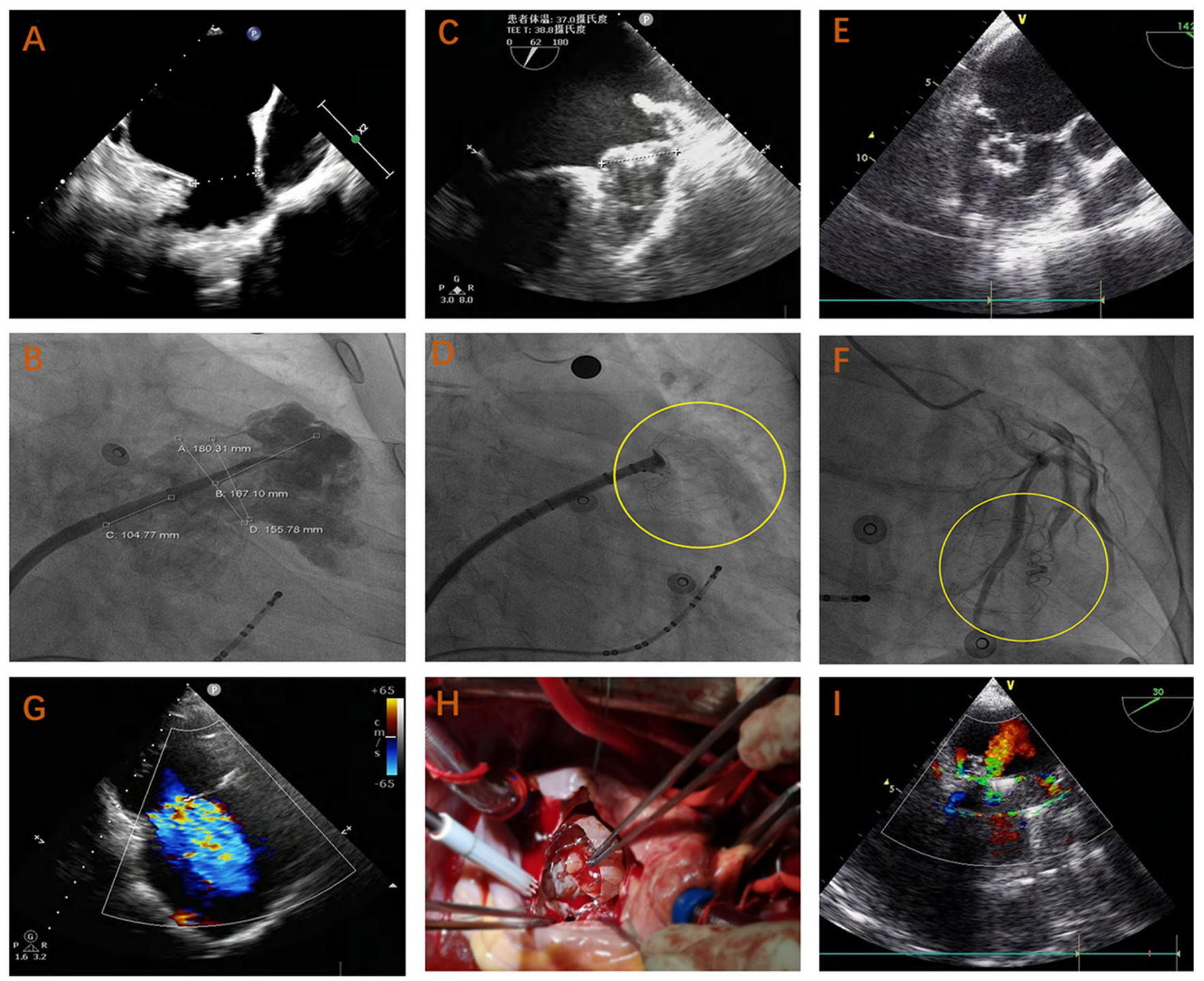

A, TEE was used to measure the inner diameter of the LAA. B, The angiography to measure the inner diameter of LAA. C, The TEE shows the state after the release of the LAAO device. D, The angiography showing the release of the LAAO device. E, The TEE shows the migration and entrapment of the LAAO device in the mitral valve. F, The angiography shows that the LAAO device is located in the LV. G, The TEE shows the massive mitral regurgitation. $H$, The intraoperative exploration revealed that the LAAO device hooked the mitral valve tendon, causing severe damage to the mitral valve. I, The TEE shows that the artificial valve works well. TEE, transesophageal echocardiogram; LAA, left atrial appendage; LAAO, left atrial appendage occlude; LV, left ventricle

has the benefit of directly closing the LAA. The present case was accompanied by severe damage to the mitral valve, which resulted in massive regurgitation. Emergency surgery was necessary to remove the LAAO device and replace the mitral valve. The patient recovered well after surgery, indicating that the present treatment is safe and effective.

\section{CONCLUSION}

Despite the obvious advantages of percutaneous intervention for the prevention of thromboembolism in nonvalvular atrial fibrillation, there is still a risk that the LAAO device could migrate and need urgent surgery. For patients elected for LAAO implantation, care should be given during the preoperative conversation and preparation for emergency surgery.

\section{REFERENCES}

Camm AJ, Lip GY, De Caterina R, Savelieva I, Atar D, Hohnloser SH, Hindricks G, Kirchhof P and Guidelines ESCCfP. 2012. Focused update of the ESC Guidelines for the management of atrial fibrillation: an update of the 2010 ESC Guidelines for the management of atrial fibrillation. Developed with the special contribution of the European Heart Rhythm Association. Eur Heart J. 33:2719-47. 
El-Gabry M, Shehada SE, Wendt D, Mourad F. 2018. Emergent surgical removal of a migrated left atrial appendage occluder. Eur J Cardiothorac Surg. 54:191-192.

Gonzalez-Santos JM, Arnaiz-Garcia ME, Arribas-Jimenez A, LopezRodriguez J, Rodriguez-Collado J, Vargas-Fajardo Mdel C, DalmauSorli MJ, Bueno-Codoner ME, Arevalo-Abascal RA. 2013. Amplatzer Amulet left atrial appendage occluder entrapment through mitral valve. Can J Cardiol. 29:1532 e5-7.

Gupta P, Szczeklik M, Selvaraj A, Lall K. 2013. Emergency surgical retrieval of a migrated left atrial appendage occlusion device. Journal of cardiac surgery. 28:26-8.

Gutierrez C and Blanchard DG. 2016. Diagnosis and Treatment of Atrial Fibrillation. Am Fam Physician. 94:442-52.

January CT, Wann LS, Calkins H, Chen LY, Cigarroa JE, Cleveland JC, Jr., Ellinor PT, Ezekowitz MD, Field ME, Furie KL, Heidenreich PA, Murray KT, Shea JB, Tracy CM, Yancy CW. 2019. 2019 AHA/ ACC/HRS Focused Update of the 2014 AHA/ACC/HRS Guideline for the Management of Patients With Atrial Fibrillation: A Report of the American College of Cardiology/American Heart Association Task Force on Clinical Practice Guidelines and the Heart Rhythm Society in Collaboration With the Society of Thoracic Surgeons.
Circulation. 140:e125-e151.

Jazayeri MA, Vuddanda V, Parikh V, Lakkireddy DR. 2017. Percutaneous left atrial appendage closure: current state of the art. Curr Opin Cardiol. 32:27-38.

Loupis AM, De Backer O, Ihlemann N, Rosenberg TS, Franzen OW, Sondergaard L. 2014. Percutaneous closure of the left atrial appendage for stroke prevention. Ugeskr Laeger. 176.

Windecker S, Kolh P, Alfonso F, Collet JP, Cremer J, Falk V, Filippatos G, Hamm C, Head SJ, Juni P, Kappetein AP, Kastrati A, Knuuti J, Landmesser U, Laufer G, Neumann FJ, Richter DJ, Schauerte P, Sousa Uva M, Stefanini GG, Taggart DP, Torracca L, Valgimigli M, Wijns W, Witkowski A. 2014. 2014 ESC/EACTS Guidelines on myocardial revascularization: The Task Force on Myocardial Revascularization of the European Society of Cardiology (ESC) and the European Association for Cardio-Thoracic Surgery (EACTS) Developed with the special contribution of the European Association of Percutaneous Cardiovascular Interventions (EAPCI). Eur Heart J. 35:2541-619.

Yilmaz A, Starinieri P, Antonic M. 2019. Thoracoscopic retrieval of an atrial appendage occlusion device after embolization into the left ventricular outflow tract and damaging the mitral valve requiring replacement. Interact Cardiovasc Thorac Surg. 28:650-651. 